\title{
Association of code status discussion with invasive procedures among advanced-stage cancer and noncancer patients
}

This article was published in the following Dove Press journal:

International Journal of General Medicine

14 July 2017

Number of times this article has been viewed

\author{
Akinori Sasaki' \\ Eiji Hiraoka' \\ Yosuke Homma ${ }^{2}$ \\ Osamu Takahashi ${ }^{3}$ \\ Yasuhiro Norisue ${ }^{4}$ \\ Koji Kawai ${ }^{5}$ \\ Shigeki Fujitani ${ }^{4}$
}

'Department of Internal Medicine, 2Department of Emergency Medicine, Tokyo Bay Urayasu Ichikawa Medical Center, Urayasu City, Chiba, ${ }^{3}$ Department of Internal Medicine, St. Luke's International Hospital, Chuo-ku, Tokyo, ${ }^{4}$ Department of Critical Care Medicine, Tokyo Bay Urayasu Ichikawa Medical Center, Urayasu City, Chiba, ${ }^{5}$ Department of Gastroenterology, Ito Municipal Hospital, Ito City, Shizuoka, Japan
Correspondence: Eiji Hiraoka Department of Internal Medicine, Tokyo Bay Urayasu Ichikawa Medical Center, 3-4-32 Todaijima, Urayasu City, Chiba, Japan 279-000I

Tel +814735 I 3I0I

Fax+8I 473526237

Email eijih@jadecom.jp
Background: Code status discussion is associated with a decrease in invasive procedures among terminally ill cancer patients. We investigated the association between code status discussion on admission and incidence of invasive procedures, cardiopulmonary resuscitation (CPR), and opioid use among inpatients with advanced stages of cancer and noncancer diseases.

Methods: We performed a retrospective cohort study in a single center, Ito Municipal Hospital, Japan. Participants were patients who were admitted to the Department of Internal Medicine between October 1, 2013 and August 30, 2015, with advanced-stage cancer and noncancer. We collected demographic data and inquired the presence or absence of code status discussion within 24 hours of admission and whether invasive procedures, including central venous catheter placement, intubation with mechanical ventilation, and CPR for cardiac arrest, and opioid treatment were performed. We investigated the factors associated with CPR events by using multivariate logistic regression analysis. Results: Among the total 232 patients, code status was discussed with 115 patients on admission, of which 114 (99.1\%) patients had do-not-resuscitate (DNR) orders. The code status was not discussed with the remaining 117 patients on admission, of which 69 (59\%) patients had subsequent code status discussion with resultant DNR orders. Code status discussion on admission decreased the incidence of central venous catheter placement, intubation with mechanical ventilation, and CPR in both cancer and noncancer patients. It tended to increase the rate of opioid use. Code status discussion on admission was the only factor associated with the decreased use of CPR $(P<0.001$, odds ratio $=0.03,95 \% \mathrm{CI}=0.004-0.21)$, which was found by using multivariate logistic regression analysis.

Conclusion: Code status discussion on admission is associated with a decrease in invasive procedures and CPR in cancer and noncancer patients. Physicians should be educated about code status discussion to improve end-of-life care.

Keywords: noncancer, end-of-life discussion, palliative care, cardiopulmonary resuscitation, DNR, quality of death

\section{Introduction}

Cardiopulmonary resuscitation (CPR) is the default standard of care in hospitals after cardiopulmonary arrest unless a do-not-resuscitate (DNR) order is written with the consent of the patient. ${ }^{1-3}$ In the USA, physicians are required to discuss and officially order a code status when patients are admitted to a hospital. ${ }^{3}$ In contrast, this practice is not obligatory in Japan. Even in the case of patients with an advanced stage of disease, some doctors discuss code status on admission and others do not. Consequently, we often observe inappropriate CPR for terminally ill inpatients in Japan, whereas some physicians do not perform CPR without discussing the code status with patients if it appears 
to be futile or inappropriate. No previous studies have reported whether code status discussion on admission decreases the use of invasive procedures and CPR among inpatients with advanced stages of illness in Japan. Several studies have found that end-of-life discussion decreases invasive treatments among terminal cancer patients. ${ }^{4-7}$ In patients who died on an oncology ward, code status documentation within 48 hours of admission was associated with less aggressive end-of-life care, regardless of the reason for admission. ${ }^{4}$ However, it has not yet been elucidated whether code status discussion on admission decreases CPR and invasive procedures among inpatients with advanced stages of diseases other than cancer. Therefore, we investigated the association of code status discussion on admission with aggressive procedures among patients with not only advanced-stage cancer, but also noncancer diseases.

\section{Methods}

\section{Ethical approval}

The study protocol for this retrospective cohort study was approved by the Institutional Review Board of Ito Municipal Hospital, Shizuoka, Japan. Informed consent from each patient was waived by the Ethics Committee because we used only retrospective de-identified patient data.

\section{Study population}

Study participants were patients who had been admitted to Ito Municipal Hospital between October 1, 2013, and April 30, 2015 , with advanced stages of diseases. Ito Municipal Hospital serves a population of 70,000 patients; $~ 4,000$ patients are admitted to this hospital per year, with approximately half of them admitted to surgical units and half to internal medicine units. Most internal medicine patients are treated by general internists. The hospital does not have a palliative care service; therefore, internists perform palliative care by themselves. Advanced-stage cancer was defined by a score of $<70$ points on the Palliative Performance Scale. ${ }^{8}$ The advanced stages of various other diseases were defined according to a previous report, which describes the characteristics of noncancer presentations with a median survival of $\leq 6$ months (Table 1). ${ }^{9}$ Patients who died in the emergency room were excluded.

\section{Data collection}

Data were collected by a retrospective review of electronic health charts. We collected age, sex, activities of daily livings (ADLs), and comorbidities. We calculated ADLs by using the Katz index, excluding the factor of incontinence, with a maximum score of 5 (independent) and minimum score of

Table I Presentations associated with a median survival of $\leq 6$ months, with effect of treatments on survival

Terminal illness presentation

Cardiovascular disease, heart failure

Hospitalization for moderate-to-severe

symptomatic heart failure, NYHA Class III or IV,

with 3 or more of the following presentations:

Age $>70$ years

Left ventricular ejection fraction $\leq 20 \%$

Serum B-type natriuretic peptide $>950 \mathrm{pg} / \mathrm{mL}$

Cardiac troponin I $>0.4 \mathrm{ng} / \mathrm{mL}$

C-reactive protein $>3.5 \mathrm{mg} / \mathrm{L}$

Fourth hospitalization for heart failure or repeat hospitalization in 2 months

Dependency of 3 or more activities of daily living or need for home care after hospital discharge

Weight loss of $\geq 2.3 \mathrm{~kg}$ within 2 months or serum albumin $<2.5 \mathrm{~g} / \mathrm{dL}$

History of cardiogenic shock, ventricular or supraventricular arrhythmia, cardiac arrest,

cardiopulmonary resuscitation, or mechanical ventilation

Systolic blood pressure $\leq 110$

Serum creatinine $>2 \mathrm{mg} / \mathrm{dL}$ or blood urea nitrogen $>40 \mathrm{mg} / \mathrm{dL}$

Serum sodium $<135 \mathrm{mEq} / \mathrm{L}$

Cardiovascular disease (ischemic, peripheral vascular, or cerebrovascular disease)

Other comorbid illness (diabetes mellitus, dementia, chronic obstructive pulmonary disease, cirrhosis, and cancer)

\section{Geriatric syndromes}

\section{Dementia}

Advanced dementia with dependency in all activities of daily living, bedbound status, urinary and bowel incontinence, decreased ability to Malnutrition (manifested by body mass index $<18.5 \mathrm{~kg} / \mathrm{m}^{2}$, decreased oral intake, or significant weight loss)

Presence of at least I pressure ulcer

communicate verbally, and admission to a hospital Evidence of at least I comorbid illness

or skilled nursing facility, with I or more of the

following presentations:
Male sex plus age $>90$ years

Placement of a nasogastric or gastrostomy feeding tube, due to inability to eat or history of aspiration pneumonia 
Table I (Continued)

\begin{tabular}{|c|c|}
\hline \multicolumn{2}{|l|}{ Geriatric failure to thrive } \\
\hline $\begin{array}{l}\text { Age }>75 \text { years, serum albumin }<3.5 \mathrm{~g} / \mathrm{dL} \text {, and } \\
\text { dependency in } \geq 2 \text { activities of daily living, with } \\
\text { admission to an acute care hospital or skilled } \\
\text { nursing facility and I or more of the following } \\
\text { presentations: }\end{array}$ & $\begin{array}{l}\text { Dependency in all activities of daily living with malnutrition (weight loss } \geq 10 \% \text { of body weight or } \\
\text { serum albumin }<3 \mathrm{~g} / \mathrm{dL} \text { ) } \\
\text { Evidence of heart failure } \\
\text { Serum creatinine }>3 \mathrm{mg} / \mathrm{dL} \\
\text { Evidence of delirium during hospitalization } \\
\text { Significant disability before hospitalization, with further functional decline posthospitalization }\end{array}$ \\
\hline \multicolumn{2}{|l|}{ Hepatic disease } \\
\hline \multicolumn{2}{|l|}{ Cirrhosis } \\
\hline $\begin{array}{l}\text { Decompensated hepatic cirrhosis and I or more } \\
\text { of the following presentations: } \\
\text { Decompensated hepatic cirrhosis with } \\
\text { hospitalization for an acute illness related to } \\
\text { liver disease and I or more of the following } \\
\text { presentations: }\end{array}$ & $\begin{array}{l}\text { Child-Pugh score } \geq 12 \\
\text { MELD score } \geq 21 \\
\text { Child-Pugh score } \geq 10 \\
\text { MELD score } \geq 18 \\
\text { Child-Pugh score } \geq 9 \text { plus dependency in } \geq 3 \text { activities of daily living and malnutrition (significant } \\
\text { weight loss and albumin }<2.5 \mathrm{~g} / \mathrm{dL} \text { ) } \\
\text { Hospitalization in an intensive care unit related to severe decompensation of liver disease, with } \\
\text { hypotension requiring the use of pressors, serum creatinine }>1.5 \mathrm{mg} / \mathrm{dL} \text {, or evidence of jaundice } \\
\text { Evidence of hepatopulmonary syndrome or rapidly progressive hepatorenal syndrome }\end{array}$ \\
\hline
\end{tabular}

\section{Pulmonary disease}

\section{COPD}

Hospitalization for a severe COPD exacerbation, with hypoxemia $\left(\mathrm{pO}_{2} \leq 55 \mathrm{~mm} \mathrm{Hg}\right)$, hypercapnia $\left(\mathrm{PCO}_{2} \geq 50 \mathrm{~mm} \mathrm{Hg}\right.$ ), and supplemental oxygen dependence, with 3 or more of the following presentations:

Age $>70$ years

Evidence of right-sided heart failure (cor pulmonale)

Repeat hospitalization for COPD within 2 months

History of intubation and mechanical ventilation

Karnofsky performance status $<60$ or dependency of 3 or more activities of daily living before the hospitalization

Need for home care after hospital discharge

Malnutrition (weight loss of $\geq 2.3 \mathrm{~kg}$, serum albumin $<2.5 \mathrm{~g} / \mathrm{dL}$, or body mass index $<18 \mathrm{~kg} / \mathrm{m}^{2}$ )

Serum creatinine $>2 \mathrm{mg} / \mathrm{dL}$

\section{Renal disease}

\section{End-stage renal disease}

End-stage renal disease on dialysis, with age $>70$ years and 2 or more of the following presentations:

End-stage renal disease without the use of dialysis, with age $>70$ years and I or more of the following presentations:

Note: Reproduced from Am J Med, 125, Salpeter SR, Luo EJ, Malter DS, Stuart B, Systematic review of noncancer presentations with a median survival of 6 months or less, 5|2.el-5|2.e6, Copyright (20I2), with permission from Elsevier.'

Abbreviations: COPD, chronic obstructive pulmonary disease; MELD, Model of End-Stage Liver Disease; NYHA, New York Heart Association.

0 (very dependent). ${ }^{10}$ "Presence of code status discussion on admission" was defined as a documentation of a physician asking the patients their preference regarding life-prolonging treatment, including intubation with mechanical ventilation and electrical cardioversion for non-cardiac arrest events and CPR for cardiac arrest events, within 24 hours after admission. Whether these procedures as well as central venous catheter placement were actually performed during hospitalization was recorded, along with the information about opioid prescriptions. Data regarding the length of hospital stay were also collected.

\section{Statistical analysis}

Continuous variables were expressed as medians (interquartile range), and discrete variables were summarized as percentages. Continuous variables were analyzed and compared by using the Mann-Whitney $U$-test, and dichotomous variables were analyzed and compared by using the $\chi^{2}$ test. 
The influence of code status discussion, on admission, on the incidence of high-burden invasive procedures, including central venous catheter placement, intubation with mechanical ventilation, and CPR, as well as opioid treatment, was evaluated by using $\chi^{2}$ test among patients stratified into cancer and noncancer groups. Factors associated with the incidence of CPR were analyzed by using multivariate logistic regression analysis. IBM ${ }^{\circledR}$ SPSS $®$ software Version 22 (IBM Corporation, Armonk, NY, USA) was used to perform the statistical analysis. $P$-values $<0.05$ were considered statistically significant.

\section{Results}

\section{Patient characteristics}

In total, 318 patients died in our hospital during the study period. We excluded 86 patients because 66 patients died in the emergency room and 20 patients did not meet the criteria of advanced-stage disease. Ultimately, 232 patients were included in this study. Code status was discussed on admission with 115 patients and not discussed with the remaining 117 patients. Table 2 presents the characteristics of these two groups. There were no significant differences in age, sex, or ADLs. Among cancer patients $(n=97), 56(67 \%)$ of them had code status discussion on admission, whereas among noncancer patients $(n=135), 59(44 \%)$ of them had code status discussion on admission $(P<0.05)$. The incidence of code status discussion on admission for each primary diagnosis was as follows: liver disease ( 6 of $14,43 \% ; P=0.223$ ), heart disease ( 5 of $24,21 \% ; P<0.01$ ), renal disease ( 0 of $2,0 \%$; $P=0.186$ ), cerebrovascular disease ( 3 of $3,100 \% ; P=0.201)$, lung disease ( 6 of $26,23 \% ; P<0.01$ ), and geriatric syndrome or dementia (39 of $66,53 \% ; P=0.63)$; ( $P$-values in comparison with the cancer group).

\section{Incidence rate of code status discussion and CPR}

On admission, 115 (49.6\%) of 232 patients had a code status discussion with their physicians, of which $114(99.1 \%)$ patients had DNR orders and $1(0.9 \%)$ patient had CPR without a DNR order (full code). Of the remaining 117 (50.4\%) patients who did not have a code status discussion on admission, $69(59.0 \%)$ patients had code status discussion and conveyed DNR orders during hospitalization. Among the remaining 48 patients with whom code status was never discussed, 32 (27.0\%) of 117 patients received CPR due to the absence of DNR orders, and 16 (13\%) of 117 patients did not receive CPR despite the absence of a documented code status discussion or DNR orders.

\section{Presence of code status discussion, life- prolonging procedures, length of stay, and opioid use}

The absence of code status discussion on admission significantly increased the incidence of central venous catheter placement $(3.5 \%$ vs. $19.7 \%, P<0.001$, odds ratio $[\mathrm{OR}]=5.65$, $95 \% \mathrm{CI}=2.01-15.8)$, intubation with mechanical ventilation

Table 2 Patient characteristics

\begin{tabular}{|c|c|c|c|}
\hline Variables & $\begin{array}{l}\text { Presence of code status } \\
\text { discussion }(n=|| 5)\end{array}$ & $\begin{array}{l}\text { Absence of code status } \\
\text { discussion }(n=\mid 17)\end{array}$ & $P$-value \\
\hline Age, median (25th, 75th percentile) & $82(75,88)$ & $80(74,87)$ & 0.294 \\
\hline Male, n (\%) & $68(59)$ & $63(54)$ & \\
\hline Independent ADLs, n (\%) & $32(28)$ & $36(31)$ & 0.67 \\
\hline \multicolumn{4}{|l|}{ Comorbidities, n (\%) } \\
\hline Heart failure & $30(26)$ & $52(44)$ & $<0.01$ \\
\hline Cerebrovascular disease & $28(24)$ & $23(20)$ & 0.43 \\
\hline Chronic lung disease & $19(17)$ & $31(27)$ & 0.079 \\
\hline Chronic kidney disease & $25(2 I)$ & $20(17)$ & 0.409 \\
\hline Cancer & $64(55)$ & $49(42)$ & $<0.05$ \\
\hline Dementia & $81(70)$ & $75(64)$ & 0.33 \\
\hline \multicolumn{4}{|l|}{ Primary diagnosis ${ }^{\mathrm{a}}, \mathrm{n}(\%)$} \\
\hline Cancer & $56(49)$ & $41(35)$ & $<0.05$ \\
\hline Liver disease & $6(5.2)$ & $8(6.8)$ & 0.78 \\
\hline Heart disease & $5(4.3)$ & $19(16.2)$ & $<0.01$ \\
\hline Renal disease & $0(0)$ & $2(1.7)$ & 0.50 \\
\hline Cerebrovascular disease & $3(2.6)$ & $0(0)$ & 0.12 \\
\hline Lung disease & $6(5.2)$ & $20(17.1)$ & $<0.05$ \\
\hline Geriatric syndrome or dementia & $39(33.9)$ & $27(23.1)$ & 0.11 \\
\hline
\end{tabular}

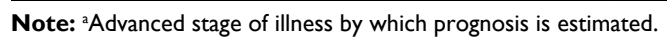

Abbreviation: ADLs, activities of daily livings. 
(1.7\% vs. $26.5 \%, P<0.001, \mathrm{OR}=15.2,95 \% \mathrm{CI}=3.7-62.1)$, and CPR (0.9\% vs. $27.4 \%, P<0.001, \mathrm{OR}=31.5,95 \%$ $\mathrm{CI}=4.3-226.4)$. Similar trends were observed in both cancer patients and noncancer patients (Figure 1A and B). The median length of stay was not statistically different between patients who did and did not have a code status discussion (17 days [10, 34] vs. 17 days [9, 30], respectively, $P=0.895$ ). Code status discussion on admission tended to increase the rate of opioid use ( $40 \%$ vs. $28 \%, P=0.072$, OR $=1.2,95 \%$ $\mathrm{CI}=0.99-1.44)$.

\section{Factors associated with the incidence of CPR}

CPR was performed in 33 (14\%) of 232 patients. Table 3 shows the factors associated with CPR. In a multivariate analysis including 5 factors (ie, age $>75$ years, primary diagnosis of cancer, pulmonary disease, geriatric syndrome or dementia, and code status discussion), only the presence of code status discussion on admission was significantly

associated with the decreased incidence of $\mathrm{CPR}(P<0.005$, $\mathrm{OR}=0.03,95 \% \mathrm{CI}=0.004-0.21$ ).

\section{Discussion}

In this study, physicians did not discuss code status with about half of the patients on admission although they were with advanced stages of diseases. It has been reported that code status discussion on admission decreases invasive treatment among terminal cancer patients. ${ }^{4-7}$ This study is the first to show that code status discussion on admission is significantly associated with the reduction of invasive procedures and CPR among both cancer and noncancer patients. This study also demonstrated that code status discussion on admission tended to increase the use of opioids, which may indicate better quality of care in our study population.

Currently, CPR is the default standard of care after cardiopulmonary arrest unless a DNR order is written with the consent of the patient, ${ }^{1,2}$ even in the end stage of illness. ${ }^{3}$ According to the recommendation by the Joint Commission,
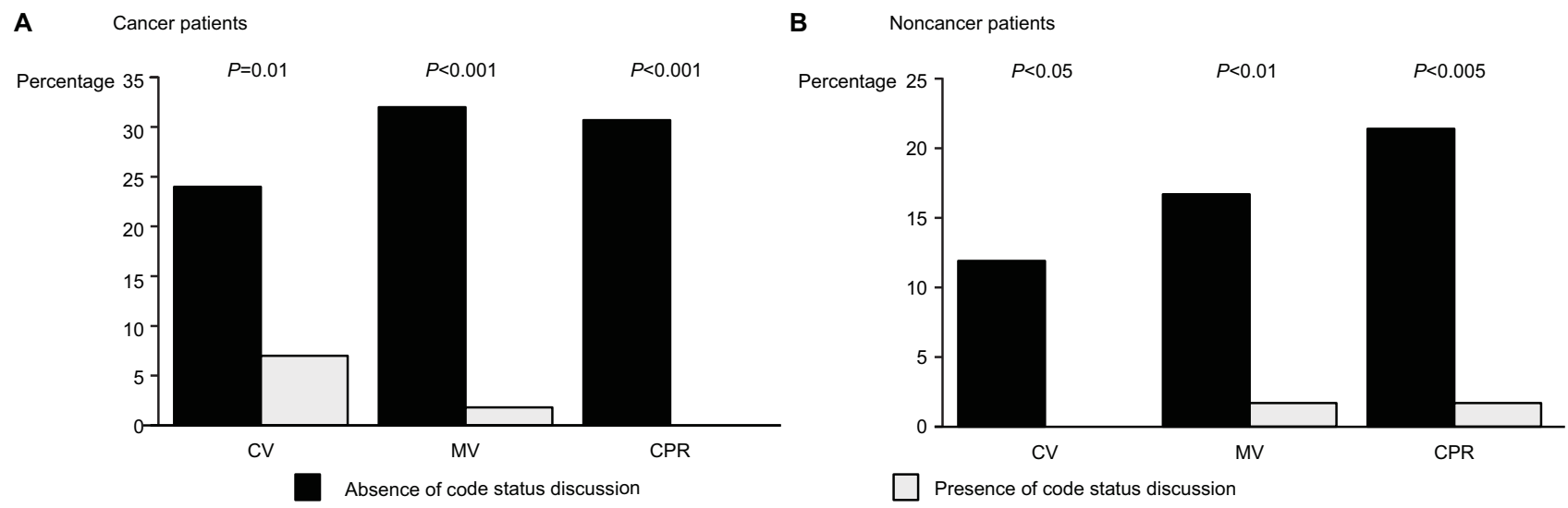

Figure I Incidence of invasive procedures and cardiopulmonary resuscitation among cancer patients (A) and noncancer patients (B) in the presence and absence of code status discussion on admission.

Abbreviations: CPR, cardiopulmonary resuscitation; CV, central venous catheter placement; $M V$, intubation and mechanical ventilation.

Table 3 Factors associated with CPR

\begin{tabular}{llll}
\hline Factor & $\mathbf{n}$ & Incidence of CPR, $\mathbf{n}(\%)$ & OR (95\% CI) (adjusted $)^{\mathbf{2}}$ \\
\hline $\begin{array}{l}\text { Age } \geq 75 \text { years } \\
\text { Primary diagnosis }\end{array}$ & 173 & $23(13)$ & $0.75(0.3-2.0)$ \\
$\quad$ Cancer & 97 & $9(9)$ & $0.42(0.15-1.22)$ \\
Liver disease & 15 & $4(27)$ & \\
Heart disease & 24 & $6(25)$ & $1(50)$ \\
Renal disease & 2 & $0(0)$ & $1.1(0.34-3.43)$ \\
Neurovascular disease & 3 & $8(31)$ & $0.38(0.11-1.28)$ \\
Respiratory disease & 26 & $5(8)$ & $0.03(0.004-0.21)^{*}$ \\
Geriatric syndrome or dementia & 66 & $1(0.9)$ & \\
Presence of code status discussion on admission & 115 & & \\
\hline
\end{tabular}

Notes: ${ }^{2}$ Adjusted for age $\geq 75$ years; cancer, respiratory disease, or geriatric syndrome/dementia as a primary diagnosis; and absence of code status discussion on admission; $* P<0.001$.

Abbreviations: $C P R$, cardiopulmonary resuscitation, $O R$, odds ratio. 
all hospitals and medical institutions are required to have formal procedures for discussing, documenting, and implementing DNR orders. ${ }^{3}$ Similar recommendations have been made by the American Society of Clinical Oncology ${ }^{11}$ and the American Medical Association. ${ }^{1}$ Legally, the US Patient Self-Determination Act of 1990 requires hospitals, nursing homes, health maintenance organizations, and hospices that participate in Medicare and Medicaid to ask whether the patient has an advance directive, to provide information about them, and to incorporate advance directives into the medical record. ${ }^{12}$ The American College of Physicians encourages physicians to routinely raise the topic of advance planning with patients who have decision-making capacity and encourage them to review their values and preferences with their surrogates and family members before an acute crisis. ${ }^{13}$ In spite of these guidelines and law, $\sim 80 \%-90 \%$ of inpatients reportedly did not have a code status discussion even in the USA. ${ }^{14,15}$

In Japan, the Ministry of Health, Labour and Welfare established a guideline for the decision-making process for end-of-life care in 2007, which was updated in $2015 .{ }^{16}$ The Guideline stresses the importance of not only the patients' medical condition, but also their values and preferences in the decision-making process. ${ }^{16}$ In our study, DNR order was discussed with only $50 \%$ of patients on admission, although they were with an advanced stage of disease. A survey conducted by the Japanese Ministry of Health, Labour and Welfare in 2013 found that $\sim 70 \%$ of respondents would not like to have invasive treatment if they become terminally ill and $\sim 70 \%$ would like to establish advance directives, although only $3 \%$ of them had. ${ }^{17}$ In another survey of middle-aged and older adults in Tokyo, Japan, $60 \%$ of respondents stated that they would like to express their wishes regarding advance directives, but $<10 \%$ had already done so. ${ }^{18}$ Therefore, physicians can play a role in helping patients to express their values and preferences regarding end-of-life issues, especially when they are with advanced stages of disease.

As patients approach death, physicians must consider treatments to improve the quality of dying and death, focusing on palliative care, quality of life, and patient and family satisfaction rather than prolonging life. ${ }^{19,20}$ In terms of palliative care for patients with advanced stages of illness, a holistic approach should be adopted, including end-of-life discussion; assessment and treatment of symptoms; psychological, spiritual, and bereavement support; and coordination of care. ${ }^{21}$ End-of-life communication should begin with establishing the goal of care. ${ }^{21}$ Communication of prognosis is also important. Without these discussions, physicians often fail in discussing the decision to withhold or withdraw aggressive care. Although physicians may worry that disclosing a realistic prognosis might make patients depressed and cause them to lose hope or that involving palliative care may reduce survival, several reports have demonstrated the opposite. ${ }^{22}$ Some patients wish to receive invasive treatment solely because they lack a full understanding of their own prognosis. $^{22,23}$ It was reported that prognostic disclosures are associated with more realistic patient expectations of life expectancy, without decrements to their emotional wellbeing or the patient-physician relationship among patients with advanced-stage solid malignancies. ${ }^{24}$ Having a realistic expectation of life expectancy was also associated with DNR orders. ${ }^{24} \mathrm{CPR}$ has been reported to decrease the quality of life among patients with advanced-stage cancer, ${ }^{25-28}$ while having a low probability of resuscitation of cardiopulmonary functions or hospital discharge for terminal cancer patients. ${ }^{29}$ End-of-life discussion was associated with a decrease in invasive procedures, including central venous catheter placement, intubation with mechanical ventilation, CPR, and increase in opioid use in this study. These changes in clinical practice could potentially decrease the medical cost and grief of the family and improve the quality of life, as previously reported. ${ }^{7,30}$ In a report, among 12 terminally ill cancer patients in whom initial code status discussion shortly after admission resulted in full code, all of them changed their status to DNR after being fully informed of their prognosis before cardiopulmonary arrest. ${ }^{4}$ This may indicate that early code status discussions resulting in full code orders may also provide patients and surrogate decision-makers the time to consider less aggressive end-of-life care and reconsider DNR orders. ${ }^{4}$ To decrease the rate of undesired CPR, it is necessary to learn appropriate prognostication and prognosis communication skills and initiate code status discussion in the early phase of advanced-stage disease. Education concerning code status is necessary in all hospitals in Japan as it faces a super-aging society. ${ }^{31,32}$

Notably, our study demonstrated that code status discussion also decreased the incidence of CPR and invasive procedures in patients with noncancer diseases. Furthermore, code status discussion occurred on admission more frequently for patients with a primary diagnosis of cancer than for noncancer patients, more specifically those with cardiac and pulmonary diseases in our study, which is consistent with the result of a previous study. ${ }^{14}$ In case of chronic heart failure or pulmonary disease, patients' health status declines slowly with occasional acute exacerbation, from which they often recover. ${ }^{33,34}$ In contrast, patients with the advanced stage of 
cancer have a more predictable progressive downward trajectory with clear prognosis. ${ }^{33,35}$ Therefore, it is more challenging to estimate the prognosis of chronic heart failure and chronic obstructive pulmonary disease than that of cancer. ${ }^{33}$ It was reported that physicians often avoided end-of-life discussion with patients with heart failure for fear of causing alarm and destroying hope. ${ }^{36}$ As a result, end-of-life discussion is often deferred until more emergent and less favorable occasions. Although heart failure has a poorer prognosis than many cancers, patients with heart failure establish DNR orders later in the disease course and receive more life-sustaining treatments, including CPR, than cancer patients. ${ }^{37}$ Chronic obstructive pulmonary disease has a similar situation to heart failure. ${ }^{38}$ Consequently, these patients often have little idea on their prognosis and may have unrealistically optimistic expectations of their prognosis. ${ }^{39,40}$ Physicians should not delay the initiation of end-of-life discussions with patients with advanced-stage cancer as well as noncancer diseases to provide better quality of care.

Our study has several limitations. First, this study was conducted in a single center; therefore, the results cannot be extrapolated to other hospitals in Japan or to other countries. Second, because of the nature of a retrospective chart review, it is not possible to determine whether the decrease in invasive procedures resulted from code status discussion itself or from a tendency for physicians who have code status discussions with patients in their daily practice to withhold invasive procedures in terminal situations. Finally, we cannot exclude the possibility that the patients with a poorer prognosis, for whom invasive procedures or CPR was obviously more inappropriate, were more likely to have a code status discussion in advance; therefore, the presence of code status discussion might be simply an indicator of poorer prognosis. However, the finding that the presence or absence of code status discussion on admission was not associated with a statistical difference in patients' length of hospital stay before death suggests that the two groups had similar prognoses. Nonetheless, we believe that our study highlights the importance of code status discussions in hospital settings to avoid unnecessary invasive procedures or CPR in cases of terminal illness.

\section{Conclusion}

Our study demonstrated that code status discussion was associated with a decrease in CPR and other high-burden invasive procedures. It also was associated with a trend for increased use of opioids among patients with advanced stages of various diseases.

\section{Acknowledgement}

This research was not funded by any source.

\section{Author contributions}

All authors contributed toward data analysis, drafting and revising the paper and agree to be accountable for all aspects of the work.

\section{Disclosure}

The authors report no conflicts of interest in this work.

\section{References}

1. Guidelines for the appropriate use of do-not-resuscitate orders. Council on Ethical and Judicial Affairs, American Medical Association. JAMA. 1991;265:1868-1871.

2. Optimum care for hopelessly ill patients. A report of the Clinical Care Committee of the Massachusetts General Hospital. N Engl J Med. 1976;295:362-364.

3. Loertscher L, Reed DA, Bannon MP, Mueller PS. Cardiopulmonary resuscitation and do-not-resuscitate orders: a guide for clinicians. $\mathrm{Am}$ J Med. 2010;123:4-9.

4. Caissie A, Kevork N, Hannon B, Le LW, Zimmermann C. Timing of code status documentation and end-of-life outcomes in patients admitted to an oncology ward. Support Care Cancer. 2014;22:375-381.

5. Mack JW, Cronin A, Keating NL, et al. Associations between end-of-life discussion characteristics and care received near death: a prospective cohort study. J Clin Oncol. 2012;30:4387-4395.

6. Bradley EH, Hallemeier AG, Fried TR, et al. Documentation of discussions about prognosis with terminally ill patients. Am J Med. 2001;111:218-223.

7. Wright AA, Zhang B, Ray A, et al. Associations between end-of-life discussions, patient mental health, medical care near death, and caregiver bereavement adjustment. JAMA. 2008;300:1665-1673.

8. Anderson F, Downing GM, Hill J, Casorso L, Lerch N. Palliative performance scale (PPS): a new tool. J Palliat Care. 1996;12:5-11.

9. Salpeter SR, Luo EJ, Malter DS, Stuart B. Systematic review of noncancer presentations with a median survival of 6 months or less. $A m ~ J$ Med. 2012;125:512.e1-512.e6.

10. Katz S, Ford AB, Moskowitz RW, Jackson BA, Jaffe MW. Studies of illness in the aged. The index of ADL: a standardized measure of biological and psychosocial function. JAMA. 1963;185:914-919.

11. Walling A, Lorenz KA, Dy SM, et al. Evidence-based recommendations for information and care planning in cancer care. J Clin Oncol. 2008;26:3896-3902.

12. Greco PJ, Schulman KA, Lavizzo-Mourey R, Hansen-Flaschen J. The Patient Self-Determination Act and the future of advance directives. Ann Intern Med. 1991;115:639-643.

13. Snyder L.; American College of Physicians, Ethics Professionalism, and Human Rights Committee. American College of Physicians Ethics Manual: sixth edition. Ann Intern Med. 2012;156:73-104.

14. Auerbach AD, Katz R, Pantilat SZ, et al. Factors associated with discussion of care plans and code status at the time of hospital admission: results from the Multicenter Hospitalist Study. J Hosp Med. 2008;3:437-445.

15. Hofmann JC, Wenger NS, Davis RB, et al. Patient preferences for communication with physicians about end-of-life decisions. SUPPORT Investigators. Study to Understand Prognoses and Preference for Outcomes and Risks of Treatment. Ann Intern Med. 1997;127:1-12.

16. Guideline: decision making process of end of life medical care. Japanese Ministry of Health, Labor and Welfare (in Japanese); 2015. Available from: http://www.mhlw.go.jp/stf/seisakunitsuite/bunya/kenkou_iryou/ iryou/saisyu_iryou/index.html. Accessed January 3, 2017. 
17. Survey of the general public's attitudes toward end of life treatment. Ministry of Health, Labour and Welfare (in Japanese); 2014. Available from: http:// www.mhlw.go.jp/stf/shingi/0000042968.html. Accessed January 3, 2017.

18. Miyata H, Shiraishi H, Kai I. Survey of the general public's attitudes toward advance directives in Japan: how to respect patients' preferences. BMC Med Ethics. 2006; 7:E11.

19. Patrick DL, Engelberg RA, Curtis JR. Evaluating the quality of dying and death. J Pain Symptom Manage. 2001;22:717-726.

20. Donaldson MS, Field MJ. Measuring quality of care at the end of life. Arch Intern Med. 1998;158:121-128.

21. Morrison RS, Meier DE. Clinical practice. Palliative care. $N$ Engl J Med. 2004;350:2582-2590.

22. Mack JW, Smith TJ. Reasons why physicians do not have discussions about poor prognosis, why it matters, and what can be improved. J Clin Oncol. 2012;30:2715-2717.

23. Weeks JC, Cook EF, O'Day SJ, et al. Relationship between cancer patients' predictions of prognosis and their treatment preferences. JAMA. 1998;279:1709-1714.

24. Enzinger AC, Zhang B, Schrag D, Prigerson HG. Outcomes of prognostic disclosure: associations with prognostic understanding, distress, and relationship with physician among patients with advanced cancer. J Clin Oncol. 2015;33:3809-3816.

25. Earle CC, Park ER, Lai B, Weeks JC, Ayanian JZ, Block S. Identifying potential indicators of the quality of end-of-life cancer care from administrative data. J Clin Oncol. 2003;21:1133-1138.

26. Earle CC, Landrum MB, Souza JM, Neville BA, Weeks JC, Ayanian JZ. Aggressiveness of cancer care near the end of life: is it a quality-of-care issue? J Clin Oncol. 2008;26:3860-3866.

27. Grunfeld E, Lethbridge L, Dewar R, et al. Towards using administrative databases to measure population-based indicators of quality of end-oflife care: testing the methodology. Palliat Med. 2006;20:769-777.

28. Barbera L, Paszat L, Chartier C. Indicators of poor quality end-of-life cancer care in Ontario. J Palliat Care. 2006;22:12-17.
29. Reisfield GM, Wallace SK, Munsell MF, Webb FJ, Alvarez ER, Wilson GR. Survival in cancer patients undergoing in-hospital cardiopulmonary resuscitation: a meta-analysis. Resuscitation. 2006;71: $152-160$.

30. Zhang B, Wright AA, Huskamp HA, et al. Health care costs in the last week of life: associations with end-of-life conversations. Arch Intern Med. 2009;169:480-488

31. Arai H, Ouchi Y, Toba K, et al. Japan as the front-runner of super-aged societies: perspectives from medicine and medical care in Japan. Geriatr Gerontol Int. 2015;15:673-687.

32. McCurry J. Japan will be model for future super-ageing societies. Lancet. 2015;386:1523.

33. Murray SA, Kendall M, Boyd K, Sheikh A. Illness trajectories and palliative care. BMJ. 2005;330:1007-1011.

34. Allen LA, Stevenson LW, Grady KL, et al. Decision making in advanced heart failure: a scientific statement from the American Heart Association. Circulation. 2012;125:1928-1952.

35. Lunney JR, Lynn J, Foley DJ, Lipson S, Guralnik JM. Patterns of functional decline at the end of life. JAMA. 2003;289:2387-2392.

36. Barclay S, Momen N, Case-Upton S, Kuhn I, Smith E. End-of-life care conversations with heart failure patients: a systematic literature review and narrative synthesis. Br J Gen Pract. 2011;61:e49-e62.

37. Tanvetyanon T, Leighton JC. Life-sustaining treatments in patients who died of chronic congestive heart failure compared with metastatic cancer. Crit Care Med. 2003;31:60-64.

38. Patel K, Janssen DJ, Curtis JR. Advance care planning in COPD. Respirology. 2012;17:72-78

39. Hole B, Salem J. How long do patients with chronic disease expect to live? A systematic review of the literature. BMJ Open. 2016;6: e012248.

40. Allen LA, Yager JE, Funk MJ, et al. Discordance between patientpredicted and model-predicted life expectancy among ambulatory patients with heart failure. JAMA. 2008;299:2533-2542.
International Journal of General Medicine

\section{Publish your work in this journal}

The International Journal of General Medicine is an international, peer-reviewed open-access journal that focuses on general and interna medicine, pathogenesis, epidemiology, diagnosis, monitoring and treatment protocols. The journal is characterized by the rapid reporting of reviews, original research and clinical studies across all disease areas.

\section{Dovepress}

The manuscript management system is completely online and includes a very quick and fair peer-review system, which is all easy to use. Visit http://www.dovepress.com/testimonials.php to read real quotes from published authors. 